\title{
Risk-benefit perception and intention to vote in favor of bicycle lanes
}

\author{
Gerardo Arturo Limón-Domínguez \\ Universidad Pedagógica Nacional, Ciudad de México, México \\ galimonxm@yahoo.com.mx
}

Oscar Valdés-Ambrosio

Universidad Nacional Autónoma de México, Ciudad de México, México

oscarva@economia.unam.mx

Héctor Daniel Molina-Ruíz

Universidad Autónoma de Hidalgo, Hidalgo, México

hmolina@uaeh.edu.mx

Bertha Leticia Rivera-Varela

Universidad Nacional Autónoma de México, Ciudad de México, México

briveravarela@yahoo.com.mx

Cruz García-Lirios

Universidad Autónoma del Estado de México, Cuidad de México, México

garcialirios@yahoo.com

\begin{abstract}
Within the framework of policies against the effects of climate change on public health, mobility policies based on zero carbon dioxide emissions have focused their interest on the implementation of bicycle lanes, the subsidy of bicycle engines and restriction of automobiles. In this sense, the objective of this paper has been to establish the reliability and validity of an instrument that measures the perceptions of risk and utility, as well as the intentions of voting in favor of electoral proposals and candidates that support the urban sustainability policy in Subject d mobility. A non-experimental, cross-sectional and exploratory study was carried out with a non-probabilistic sample selection of 250 residents of the metropolitan area of Mexico City. From a structural model. The factors cited were found to correlate positively and significantly, but it is recommended to extend the study to the contrast of the model in other scenarios with local elections and mobility policy based on the use of the bicycle.
\end{abstract}

Keywords: Local development, sustainability, co-governance, model, Delphi. 


\section{INTRODUCTION}

The project is part of the discipline of Social Work, an area of documentary studies and complexity, but includes concepts from social psychology, environmental sociology and solidarity economy.

This is how the perception of risk-benefits and voting intentions are, from the perspective of social psychology, the result of the interrelation between groups, as is the case of those who favor zero-emission mobility policies. carbon to the atmosphere. The decisions to use an ecological transport are due to the intensive use of a technology that makes zero emissions possible, but above all to the meaning of these technologies.

In this way, positive attributions to the science produced by zero-emission technologies favor a trend in favor of bicycle lane policies, shared mobility strategies or subsidies in the installation of bicycle engines, but this social construction of the zero emissions must be complemented by the meaning of the environmental and atmospheric footprint of transport users that emit carbon dioxide into the atmosphere.

From the environmental sociological approach, the social construction of nature is different from the social construction of the ecological balance since, the first one supposes a means or instrument of domain of the humanity, while the second implies the care of the environment for the future generations of humans, descendants of those who today make the decision to reduce their emission of carbon dioxide and the atmospheric footprint

However, both the social construction of the environment and the meaning of the use of zero-emission transport, as in the case of cycle paths, imply a logic of cost-benefit without which the advance of science and humanity could not be explained. that supposes greater and better options of protection and conservation of the environment.

This is an economic environmental logic of cost and benefit that conditions the viability of environmental policies, prevention strategies and self-care promotion programs through the intensive use of bicycles.

Well, the Social Work approach takes up the contributions of the three disciplines and integrates them into an intervention model with the aim of articulating civil demands in state institutions and translating government policies into civil organizations charged with incentivizing subsidies and condonations aimed at reducing the atmospheric footprint such as the use of bicycle lanes.

Governance human development, understood as a process of co-government, co-management and co-responsibility that considers resources and services as common, is the object of study and research of this work.

The governance of human development supposes a scenario of co-government of conflicts, freedoms, opportunities, capacities and responsibilities of management as 
self - management oriented towards the conservation of spaces and species (Carreón et al., 2016).

In the context of the effects of climate change on public environmental health, local governments have implemented policies and strategies to reduce such effects, but the management and administration has been predominantly state, excluding citizens or at best confining them to participate in the evaluation of the performance of institutions or officials, bypassing the rights that guarantee and compel civil society to propose and discuss a common future with their authorities (García, 2013) .

As a result, the proposals for self-government, self-management and self-administration of natural resources and public services have been built in opposition to the laws, institutions and state decisions, even though the media have spread political corruption as the obstacle to the sustainable local development (García, Carreón \& Hernández, 2016a).

Therefore, from the academy is necessary the integration of self-government with the rector of the State in matters of co-government, co-management and co-management of natural resources and public services in order to reduce the impact of climate change on environmental public health (Garcia et al. al., 2012).

\section{THEORY OF SUSTAINABLE LOCAL DEVELOPMENT}

The theoretical and conceptual frameworks that explain the governance of human development are: 1) theory of spatialities, 2) theory of habitus and 3) theory of capabilities.

The theory of spatialities, for the purposes of this writing, refers to the explanation of the fetishization of spaces to which they are attributed a power that differentiates them as is the case of residing or aspiring to reside in the city with respect to the periphery or the field.

This is how a spatiality supposes an excessive attribution of privileges with respect to processes, things, objects or people. In this way, the fetishization of spaces generates the exclusion of people, although they also exclude species, spaces, things, processes or objects by the simple fact of attributing them a place outside a city (García, Carreón \& Hernández, 2016b).

However, the theory of spatial does not realize that such power atributions urban spaces becomes $\mathrm{n}$ of habitus both inherited and learned. This is so because the dispositions of those who reside in cities are transferred from generation to generation and are molded in the family, school or work relationship (Bourdieu, 2002). 
In this way, the exclusion from the attribution of a superiority to the cities, synthesized in the perceptions of the quality of life or the residential aesthetics, is a negative disposition toward everything that is not in the city, but it is also a disposition that is learned (García et al., 2013).

By interacting, residents of a city develop skills and knowledge about what they consider security services and comfort that lead them to ennoble their choice of residence with respect to those living in areas without services considered essential as paving, sewers, drainage or potabilization (García et al., 2014).

Both habitus, inherited and learned explain the choice of a habitat, a stay of residence, as well as a journey towards comfort and a return to the place of first residence, but they do not explain the use of opportunities to buy or sell residence, nor the entertainment or entertainment that involves solidarity tourism or the search for employment or studies in cities (García et al., 2016).

The theory of capabilities warns that public services; health, education, employment, housing or entertainment, apparently distinctive of a city with respect to the periphery or the countryside, are products of the skills and knowledge that a resident develops from a logic of scarcity or abundance.

The logic of scarcity not only explains the inefficiency and inefficiency of the State's rector, the illegitimacy of its urban policies or the ineffectiveness of its strategies, but also warns that, in a context of austerity or contingency, residents organize themselves to do in the face of the shortage crisis, although encouraged by the idea that they will conserve natural resources to survive the growing ungovernability(García et al., 2017).

In contrast, the logic of abundance, although it refers to a series of beliefs that the natural environment is abundant and that residents must optimize such resources, raises the development of skills and knowledge necessary to import resources from other places. sue (García, Valdés \& Sandoval, 2016).

The logic of scarcity supposes a solidary cooperation while the logic of abundance suggests a competition for the resources of the immediate and surrounding environment (Hernández et al., 2014).

Therefore, the governance of human development, from the approaches reviewed, refers to perceptions of scarcity or abundance of resources and their reflection on the quality of local services.

The work is inscribed in developmental humanism (freedoms, capacities and responsibilities), structuralist constructivism (habitus, capitals and fields) and Marxist urbanism (partialities). 
- Freedoms, capacities and responsibilities for the appropriation of the city (spaces and water resources).

- Habitus, capitals and fields where conflicts are generated by the redistribution of resources and spaces in the city (aquifers, networks and pipes).

- Partialities for the governance of the local resources of the city (awareness for the equitable distribution of water).

The proximity of the concepts to the everyday styles will allow to discuss the importance of the political system of governance in reference to the eco-city economic system. In this sense, it is necessary to open the debate on social inclusion through the right to a city, mainly to natural resources and essentially to water resources as elements of local sustainable development.

The city as a scenario of symbols, meanings and meanings around which the asymmetries between public policies and urban lifestyles are represented. The city is a scenario of resources that increase capacities, but also increase responsibilities.

Studies related to real estate services; spatial and technological indicate that the size of the houses and technology of their facilities, to be increasingly reduced the first and more automated the second, facilitate fluvial catchment and recycling, but inhibit the storage and reuse of water. Provision capacity seems to encourage the irresponsibility of waste of water.

The interrelation between resources, services, scenarios, skills, knowledge and responsibilities that would make a governance system necessary suppose a balance between the mentioned factors is regulated by the State, supervised by the citizens and financed by the market.

However, from a developmental policy framework in which freedoms will give way to capabilities and responsibilities. This process seems to be inhibited given the scarcity of natural resources in cities. That is, the availability of resources, being an objective fact rather than a subjective one, influences the lifestyles of the users who inhabit the cities. Such scarcity phenomenon activates public policies that seek to supply resources to one social sector to the detriment of another.

In response to the exclusion or marginalization of public services, the segregated population constructs habitus intuito, adopts lifestyles from which they will confront symbolically and actively with the authorities. Protests, closures, rallies, demonstrations, marches, physical or verbal confrontations are the result of scarcity of resources, public policies and lifestyles or habitus of citizens.

Studies on life styles in cities in terms of shortage, saving and water reuse show that availability of less than 50 liters per person per day increases austerity, but increases 
confrontations with local authorities; kidnappings of pipes, closures of avenues, boycotts to networks and clandestine takes. Citizens segregated from water spaces and public services, develop skills and strategies to demonstrate the situation in which they find themselves, express their indignation and appropriate spaces.

Within the framework of water conflicts between authorities and users, citizens' lifestyles in a situation of scarcity are a consequence of public policies. The city is a field of interrelation between capitals and socially constituted habits. In this way, economic and political capitals are confronted with natural and citizen capitals. That is, the market and the State require aquifers that supply the industry and private services as publics of the city, but the availability of water, through the recharge of aquifers, is increasingly lower than international standards or registries. national historical Such a scenario explains the emergence of habitus or lifestyles in vulnerable, marginalized or excluded sectors.

However, lifestyles are conjunctural, emerging and inherent to a group or social agent. In other words, in a situation of scarcity and shortage, austerity underlies and similarly disappears in a situation of water sustainability in which the recharge of aquifers would guarantee the human and local development of the demarcations of a city. Such an approach is insufficient if it is necessary to understand the historical process that led cities to concentrate resources, services, lifestyles and capacities.

The city as a symbolic scenario in which the relations of production materialize. The city concentrated the asymmetric economic relations between the classes that own the means of production and the labor force. In this sense, the city is a scenario of industrial production rather than services since the asymmetric relations between the bourgeoisie and the proletariat prevail over other asymmetric relations. Therefore, the awareness of space is no longer necessary to appropriate the factory, but the city that houses it. The right to the city would be the extension of the right to a symmetrical production relationship.

If the labor force only appropriates the means of production, the spaces would be only an accessory to the class struggle rather than a constitutive element of the differences between these classes.

The redistribution of resources and their impact on human, local and sustainable development is explained from the differences between individuals (sex, age, abilities, education, locality) determine the freedoms that individuals require to develop sustainably. In this sense, capacities are knowledge and experiences derived from the interrelation between individual characteristics, resources and spaces. As resources are scarce, capacities are decimated, and spaces are conflict scenarios since the State limits freedoms to guarantee a proportional distribution of resources. 
In the case of water, the capacities play a fundamental role since the daily use of water implies the development of life styles or habitus that can help to counteract the situation of scarcity and shortage. In this sense, the explanation of the discrepancies between local water supply policies and self-management actions, closure of floods, network intervention, sequestration of pipes and boycotts to the system are the result of transformations of resources and spaces to the that a sector of the citizenry does not have access.

If capacities and habitus are indicators of the conflicts between citizens' expectations and public decisions, then appropriation of spaces for debate on the right to the city, its resources and water supply systems as well as water distribution is fundamental.

In this sense, the category of power to explain the differences between the relations of symbolic and material production. The city stands as a symbol of power that homogenizes the relations of production because the material conditions for it are already spatially pre-established. That is, spatial relationships are relations of power, but not communicative or discursive relationships, but material, although their fetishization makes them appear as tangible objects, but only at a discursive level, such relationships could be transmuted.

The fetishism of space as a commodity undermines the principle according to which the material conditions of existence determine the ideological superstructure. This is so since the exaltation of objects is inherent in the value of their use. The space, real or symbolic would have a use value, but not of change, although the interesting thing about its fetishization is that it indicates the degree of alignment to capitalist production relations over any other type of relations in which the spaces were not transformed into merchandise.

In a certain way, the capacities and the habitus would be precedents to the alignment and would be indicated by their degree of fetishistic representation of space. If capacities and habitus are skills circumscribed to resources and spaces, then the alignment would be the result of the scarcity of resources and the asymmetric distribution of resources. The scarcity of fetishized water in short supply would mean the emergence of saving skills or dosage habitus, but such a process would inhibit the representation of conflict and social change. that is, scarcity, shortage, confrontation or boycott indicate a pseudo-conflict as it is resolved by supplying pipes, the distribution of jugs, the regular provision of water or the granting of vouchers for the purchase of water. The contradictions between public policies and lifestyles, derived from the demand of the pharmaceutical, soft drink or beer market, are reduced to distribution relationships rather than production or space allocation.

The fetishization of space prevents observing the differences between social relations and their stratification based on spatial and economic segregation mecha- 
nisms. Therefore, it is necessary to consider as a socio-historical complement to the categories of habitus and capacities which are a-historical considering them emerging or underlying to the absence of freedoms or the generation of abstract conflicts between the structure (public policies) and the agency.

The systems of governance of natural resources, mainly water, to the lifestyles of the users in reference to the public policies of water supply and irregular supply. In this regard, the reconceptualization of local governance systems will allow greater equity between the sectors through a normative legal framework of the right to the city in general, natural resources and public services at the local level and the comfort of water in the particular.

However, the urgency of a fairer political system around the citizenship of the cities, ecocity projects are multidimensional and, in this diversity, lies its complexity (García et al., 2017).

The ecocity concept is multidimensional. It has been understood as an economic, political and social system to reduce the ecological footprint of previous generations about the capacities of previous generations, a space limited to one million inhabitants, whose activities are agriculture and industry as a function of water availability, although conflict scenario, recycling is considered as its main development tool (García et al., 2013).

The eco-city concept is related to others of a socio-historical nature. Together with the categories of freedoms, capacities, responsibilities, habitus, capitals, fields and spatialities, the concepts of governance, segregation, sustainability, centrality, inclusion, periphery and surplus value will make it possible to conceptualize the problem of scarcity, marketocracy and shortage in the demarcation of study (García et al., 2014).

If the concepts used are considered, a governance system oriented towards the ecocity is opposed to segregation via the relocation of social sectors from the naturalization of their exclusion but is closer to local development since the term sustainability incorporates the system of government as rector of the resources and services of the ecocity. Rather, a governance system is developed in small localities such as the neighborhood or the periphery to extend to the center of the city. This is how the ecocity indicators would be those related to sustainability and inclusion. In this sense, studies on sustainability and eco-city projects seem to demonstrate the viability of the terms based on heterogeneous indicators (García et al., 2016).

Latin American studies on scarcity, partocracy and public policies on water resources in cities have used various instruments to measure indicators of local water sustainability. The management of water resources; the ethnic appropriation of the urban space; population density as a factor of residential sustainability; national identity as an 
argument for the design of buildings; the reordering from the inclusion and spatial exclusion, the bi-oceanic peri-urban tourism policies; the perception of peri-urban risk; The segregation of public squares and the representation of the city according to social strata are examples of the empirical relevance of studying scarcity, marketcracy and public policies around the water resources of Mexico City (García et al., 2014).

Empirical studies on sustainability and eco-city have incorporated the symbolic and representational dimension of those who consume resources and therefore evaluate public services. In this way, studies have focused on the impact of public policies on the lifestyles of indigenous peoples, communities, neighborhoods and peri-urban localities about centrality and territorial ordering. In such a process, qualitative studies have replaced the quantification of spaces, instruments such as plans, records and maps have been replaced by in-depth interviews. The investigation of spatial relationships and natural resources has now incorporated representations of public services as a fundamental element of the governance system through the establishment of tariffs for urban services (Carreón et al., 2016).

The relations of appropriation, transformation and distribution of resources and spaces in their development process encouraged the differentiation of social classes. As the differences were exacerbated, the segregation of the spaces protected the appropriate and transformative differences at the same time as it enhanced the distributive differences of the resources, mainly the water ones. This process confronted public policies against lifestyles privileging market demands (Hernández, et al., 2014).

Regarding the situation of scarcity and shortage generated by public policies that adjusted to market demands, the marginalized, excluded and vulnerable sectors developed skills, knowledge and strategies for appropriating spaces (aquifers, facilities, networks) to supply and confront the authorities for the regularization of the service. In this framework, the transformation of water resources was delegated to the federal government and the collection of the service from the local government (García et al., 2012).

In this sense, the shortage of water and the increase in tariffs oriented the water conflicts towards the forgiveness of debts, the implementation of meters, the repair of visible leaks, the protection of facilities, the control of demonstrations and agreements between authorities delegations with representatives of the users. In contrast, aquifer concessions, river recycling and collection technology, investment in infrastructure, detection of imperceptible leaks, contamination and overexploitation of aquifers, water cultures and real estate deregulation were ignored as problems that impede the sustainability of the city (García et al., 2014).

Within the framework of eco-city projects and the evaluation of their governance systems, mainly public policies on natural resources, essentially water resources, the 
Human Development Index aims to observe, measure and compare freedoms, capacities and responsibilities, but in the best of cases it only records the amount of public goods that would demonstrate local sustainability. Therefore, an index describing sustainability with emphasis on water resources is required, referring to its availability, extraction, distribution, consumption, reuse, recycling and tariff as constitutive elements of a local governance system (García et al., 2016).

A model is a representation of the trajectories of relationships between the factors used in the state of the art.

The governance of human development, indicated by the fields of capacity of liberties, is a capacity for opportunities, fields of fetishization of capacities and spaces of responsibility capacity implies the construction of a system of co-government, co-management and co-administration.

The fields of capacity for freedom suggest that, in sustainable local development, governments promote and guarantee economic, political, social, labor or sexual rights based on the skills and knowledge of their governed. In this sense, the relationship between governors and the governed is established in power fields in which both actors influence each other.

Therefore, opportunities for generating opportunities are gestated to the extent that the political and social actors resolve their asymmetries based on the establishment of a public agenda in which the issues to be managed and managed are shared.

However, the fields of fetishization of capabilities warn that although freedoms and opportunities are more widespread and protected in cities, this does not explain the differences between centrality and the periphery or semi periphery. As a result, an attachment to urban resources and services develops.

The spaces of responsibility capacities are the result of co-government. That is, the reconciliation of interests between the parties to the conflict. Therefore, they indicate co-management and co-administration as co-responsibility is a symptom of governance.

The relationship between pro-environmental behavior and voting intention in favor of sustainable proposals has been addressed from the attachment to the place and the quality of life, indicated by environmental satisfaction. In this sense, those who have a greater attachment to the place not only carry out low intensity pro-environmental behaviors such as the separation of waste, but also involve themselves in civil organizations that influence the conservation policies of public places.

For compared groups of surfers with non-surfers and found significant differences with respect to low effort (waste separation) as a high effort (activism) around conservation, concluded that recreational groups are more prone to environmental conservation, achieving high levels of satisfaction with the surfer experience. The recreational 
and conservationist groups that supported candidates promoting the vote, influenced the intentions of local voters. To the extent that the image of the candidate is close to recreational and conservationist groups, the intentions of voting in favor of their proposals increase.

The image of candidates that determines the electoral preferences and intentions lies in a) promises of conservation of recreational and tourist spaces; b) moral support to recreationalist and conservationist movements; c) management of spaces for recreation and recreation; d) experience in the administration of protected areas.

Since the image of the candidate is the predictor of the intention to vote, consensus expectations about its performance and the expected benefits of such performance suppose predictors of voting intention and pro-environmental behavior.

Pérez et al., (2017) established a direct relationship between the intention to vote with respect to the expected benefits and expectations of consensus around the image of candidates as responsible and environmental leaders in social networks. The incidence of the expected benefits on the intention to vote implies the use of the bicycle as a prediction of the intention to vote. The use of the bicycle when being linked to a recreation determines the support to candidates with experience in management and administration of spaces and systems of sustainable transport or of zero emissions, as well as of politicians with an image of cycle path users.

The differences between the expectations of a sample of voters of a municipality without and with cycle-track in comparison to the observations of a locality in relation to the image of candidates and intention to vote in the presidential elections to be held in 2018

The voters who reside in the municipality without and with cycle-track have a positive image of the candidates and their intention to vote will be in favor of those who include proposals for zero-emission mobility, showing that the theory explains the phenomenon in the context study.

Expectations about the presidential elections to be held in 2018 and the installation of cycle routes will not affect the voter samples to maintain an image and unfavorable vote intention to any candidate, even if some include proposals for zero emissions mobility.

\section{METHOD}

A documentary study was carried out with an intentional selection of sources indexed to national repositories, assuming that their period of publication places the informative source in a select group to discuss the relationships between the variable's indicative of the research object: a model for the study of the sustainable local develop- 
ment. The limits and scope of the search, selection, processing and modeling of the information are warned, suggesting a more sophisticated and extensive procedure.

A complexity model was established, carrying out a documentary research that considers the literature published from 1974 to 2017, as well as the inclusion of the concepts "spatiality", "habitus" and "capacity". The selected information was processed using the Delphi technique, which consists of the selection, synthesis and integration of the data consulted.

A non-experimental, exploratory and transversal study was carried out. A non-probabilistic lesson of 250 residents of two municipalities of the State of Mexico, 125 of a municipality with chilliest and 12 was carried out. 5 residents of another municipality without bike path. The time of residence, the elector's credential and the vote in previous elections were considered. $70 \%$ of the interviewees are men and the remaining $30 \%$ are women; $52 \%$ are under 18 years old, $33 \%$ are between 19 and 29 years old, the remaining 15 are between 30 and 65 years old. $40 \%$ completed primary school only, $24 \%$ completed secondary school, $19 \%$ completed high school and the remaining $17 \%$ completed a university degree. $62 \%$ entered less than 3500 pesos per month, $28 \%$ entered between 3500 and 7000 pesos per month and the remaining $10 \%$ entered more than 7000 pesos per month. $80 \%$ do not have a bicycle and the remaining $20 \%$ have a bicycle, but only $5 \%$ use it for transportation.

The Risk and Benefits Perception Scale of Carreón (2016) was used, which measures the image of politicians around proposals for sustainable mobility or zero emissions, focused on the utility of the bikeway or cycle paths, parking and road safety. It includes 21 items with six response options ranging from $0=$ not at all probable, $1=$ very unlikely, 2 $=$ unlikely, $3=$ neither improbable nor probable, $4=$ not very likely, $5=$ very unlikely.

The intention scale of voting of Carreón (2016) was used, which includes 28 items related to 1) the management of sustainable mobility or zero emissions and 2) the administration of transport safety. It includes six response options ranging from $0=$ not at all likely, $1=$ very unlikely, $2=$ unlikely, 3 = neither probable nor unlikely, 4) unlikely, $5=$ very unlikely.

Residents were surveyed at their home, considering the proximity to the bike path or cycle path, as well as some other transport and mobility system, guaranteeing in writing the confidentiality of their data and the anonymity of their responses, as well as the warning that the results of the study would not affect their quality of life in terms of transport, mobility and safety. The information was processed in SPSS version 17.0 and AMOS version 4.0

Reliability estimates were made with the Cronbach alpha parameter in order to establish the internal consistency of the instruments. Validity was calculated with an exploratory factorial analysis of principal axes with promax rotation to reduce data and 
establish factors. Correlations were made between socioeconomic factors and scales of expectations and intentions. Multiple regressions were estimated to observe the dependency relationships between the factors and an analysis of variance was calculated to establish differences between the groups.

\section{RESULTS}

Table 1 shows the psychometric properties of the instrument that measures perceptions of risk and benefits, as well as voting intentions in favor of zero-emission mobility policies, focused on the installation of bicycle lanes.

TABLE 1.

Instrument descriptions

\begin{tabular}{cccccccc}
\hline $\mathbf{R}$ & $\boldsymbol{M}$ & $\mathbf{S}$ & $\mathbf{K}$ & $\mathbf{A}$ & $\boldsymbol{F 1}$ & $\boldsymbol{F 2}$ & $\boldsymbol{F 3}$ \\
\hline $\mathbf{R} 1$ & 3.23 & 1,32 & 1,31 & 0,712 & & & 0.394 \\
$\mathbf{R 2}$ & 3.36 & 1,03 & 1,32 & 0.731 & & & 0.394 \\
$\mathbf{R 3}$ & 3.40 & 1,05 & 1,43 & 0.703 & & & 0.357 \\
$\mathbf{R} 4$ & 3.45 & 1,28 & 1,40 & 0.724 & & & 0.325 \\
$\mathbf{R 5}$ & 3.01 & 1,31 & 1,42 & 0.736 & 0.346 & & \\
$\mathbf{R 6}$ & 3,27 & 1,24 & 1,59 & 0.751 & 0.374 & & \\
$\mathbf{R 7}$ & 3.92 & 1,40 & 1,30 & 0,738 & 0.382 & & \\
$\mathbf{R 8}$ & 3.54 & 1,30 & 1,24 & 0.762 & 0,348 & & \\
$\mathbf{R 9}$ & 3.92 & 1,59 & 1,54 & 0.704 & & 0.325 & \\
$\mathbf{R} 10$ & 3.03 & 1,39 & 1,49 & 0.716 & & 0.334 & \\
$\mathbf{R} 11$ & 3.02 & 1,23 & 1,24 & 0,726 & & 0.384 & \\
$\mathbf{R 1 2}$ & 3.83 & 1,43 & 1,31 & 0.705 & & 0.394 &
\end{tabular}

$\mathrm{R}=$ Reactive, $\mathrm{M}=$ Median, $\mathrm{S}=$ Standard Deviation , $\mathrm{K}=$ Kurtosis, $\mathrm{A}=$ Crombach's alpha, removing the value of the item. Extraction method: mainraxes, promax rotation. Adequacy and sphericity $\int \mathrm{X}^{2}=324.34(12 \mathrm{gl}) \mathrm{p}=0.000$; KMO $0,678 \mathrm{~J} \mathrm{F1}=$ Perception of risks $(28 \%$ of the total variance explained and alpha of 0.771$)$, F2 = Perception of Benefits ( $18 \%$ of the total variance explained and alpha of 0.765$), \mathrm{F} 3=$ Intent to vote (14\% of the total variance) expl $\mathrm{i}$ each and alpha of 0,778 ). All the items are answered with five response options ranging from $0=$ not at all probable, 1 = very unlikely, $2=$ unlikely, $3=$ moderately probable, $4=$ very probable and $5=$ quite probable.

Once the factors were established, they were compared in a correlational and reflective model. The risk factor is more associated with the intention to vote that the perception of benefits, although this also has a positive and significant relationship (see Table 2 and Figure 1). 
TABLE 2.

Correlations and covariations

\begin{tabular}{ccccccc}
\cline { 2 - 7 } & $\boldsymbol{F 1}$ & $\boldsymbol{F 2}$ & $\boldsymbol{F 3}$ & $\boldsymbol{F 1}$ & $\boldsymbol{F 2}$ & $\boldsymbol{F 3}$ \\
\hline $\boldsymbol{F 1}$ & 1,000 & & & 1,987 & & \\
$\boldsymbol{F 2}$ &, $321^{* *}$ & 1,000 & &, 435 & 1,897 & \\
$\boldsymbol{F 3}$ &, $432^{* *}$ &, $317^{*}$ & 1,000 &, 439 &, 412 & 1,789 \\
\hline
\end{tabular}

$\mathrm{F} 1=$ Perception of risks, $\mathrm{F} 2=$ Perception of Benefits, F3 = Intent to vote: ${ }^{*} \mathrm{p}<, 01 ; * * \mathrm{p}<, 001 ; * * * \mathrm{p}<, 0001$

Source: Elaborated with data study

\section{FIGURE 1}

Structural model

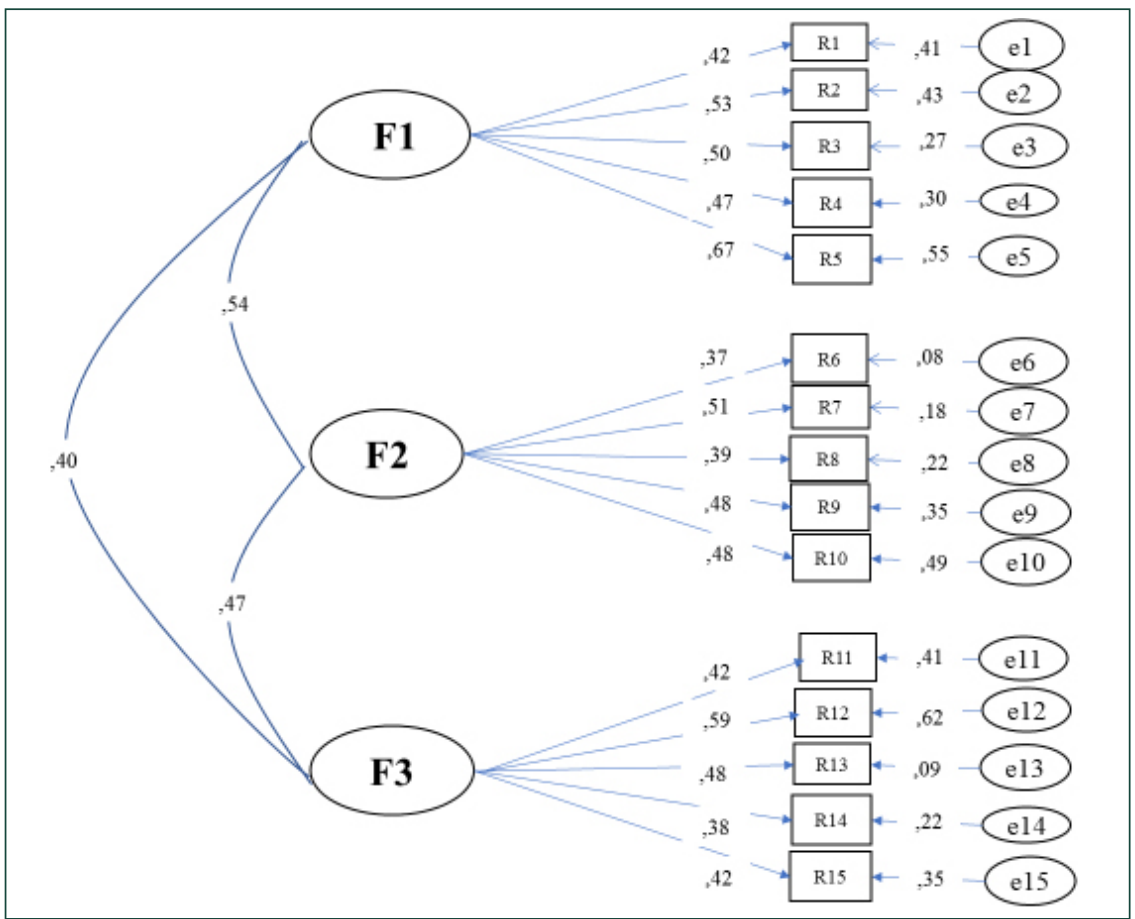

F1 = Perception of risks, F2 = Perception of Benefits, F3 = Intent to vote: $\mathrm{R}=$ reactive, $\mathrm{e}=$ Error: $\cap$ relations between factors; $\leftarrow$ relations between errors and indicators; $\rightarrow$ relations between factors to indicators Source: Self-made.

The adjustment parameters $\rho \mathrm{X}^{2}=124.35$ (22gl) $\mathrm{p}=0.006$; GFI $=0.990$; $\mathrm{CFI}=$ $0.995 ; \mathrm{RMSEA}=0.009 \mathrm{~J}$ suggest the acceptance of the null hypothesis which warns the theoretical explanation of the observed phenomenon. 


\section{DISCUSSION}

The contribution of this work to the state of knowledge lies in establishing a model for the e studio of 1 to $\mathrm{s}$ zero emission policies regarding the implementation of bicycle lanes and its orientation towards governance development human, but the type selection the sample, the search in national repositories and the analysis technique limit the model, for which an informative selection is required in international repositories with a more sophisticated analysis technique such as data mining.

However, the type of exploratory study, the type of intentional sample selection and the type of factor analysis of principal axes with promax rotation limit the results to the context and to the study sample. It is necessary to carry out an extension of the study for the contrast of the model and its adjustment to the empirical data observed in the context of the investigation. It is a probabilistic selection with a principal component analysis with variamax rotation. Such a strategy would allow the inclusion of theoretical, conceptual and empirical frameworks related to sustainable local development such as social mobilization, collective action, civil spheres and citizen networks in conflict and agreement with their authorities.

\section{CONCLUSION}

The aim of this study was to establish the reliability and validity of an instrument that measures the perception and intention to vote in favor of policies and candidates who support as mobility strategies zero emissions based on the implementation of the s bikeways. The results show that the expected risks have a greater correlation with the intention to vote, but not very different from the incidence of the perception of benefits.

That is, in the context of the study, a peculiarity not observed in other scenarios seems to be evident, as is the case of ambivalence, which assumes that the electorate is divided into a group that supports zero emission reduction strategies but coexists with another group that seems to be dissatisfied with the proliferation of cyclists and the abandonment of traditional mobility.

\section{REFERENCES}

Carreón, J., Hernández, J., Quintero, M.L., García, C. \& Mejía, S. (2016). Knowledge networks around organizational complexity: learning self-regulation, dissipation, adaptability and dynamism between changes. Prospects in Psychology, 2 (2), 57-70. 
García, C. (2013). The knowledge network in a university with a system of professional practices and a technological-administrative social service. Fundamentals in $\mathrm{Hu}$ manities, 14 (1), 135-157.

García, C., Carreón, J. \& Hernández, J. (2016a). Specification of a sociopolitical complexity model. Political Psychology, 14 (16), 40-59.

García, C., Carreón, J. \& Quintero, M. (2016b). Contrast of a model of the determinants of the managing personality. Without End, 16, 70-85.

García, C., Carreón, J., Hernández, J., Montero, M. \& Bustos, JM (2012). Systems of political complexity. Social Work Today, 65, 39-48.

García, C., Carreón, J., Mecalco, J., Hernández, J., Bautista, M. \& Méndez, A. (2014). Complex political systems: Implications for sustainable public security. Actions and Social Investigations, 34, 183-206.

García, C., Carreón, J., Sánchez, A., Sandoval, F. \& Morales, M. (2016). Reliability and validity of an instrument that leadership and educational management. Ehquity, 5, 109-130.

García, C., Juárez, M., Sandoval, F. R. \& Bustos, J. M. (2017). A psychological approach to environmental complexity: Specification of a model of community stress and resilience. Community, 14, 75-95.

García, C., Morales, M. L, Bustos, J. M, Carreón, J., Limón, G. A \& Hernández, J. (2013). Systemic foundations of political complexity. Approaches, 25 (1), 7-23.

García, C., Sandoval, F. R, Rivera, B. L, \& Limón, G. A (2017). Complexization of a model for the study of environmental resilience. Without Borders, 10 (25), 1-13.

García, C., Valdés, O. \& Sandoval, F. R. (2016). Algorithmic and neguentropic complexity in models that explain social suffering in Mexico City. Margin, 81, 1-6.

Hernández, J., Carreón, J., Morales, ML, Aguilar, JA \& García, C. (2014). Sociopolitical complexity of public transport. Implications for sustainable local development. Reason and word, 86, 4, 49-468. 